\title{
The advantage of first mention in Spanish
}

\author{
MANUEL CARREIRAS \\ Universidad de La Laguna, Tenerife, Spain \\ MORTON ANN GERNSBACHER \\ University of Wisconsin, Madison, Wisconsin \\ and \\ VICTOR VILLA \\ University of Texas, San Antonio, Texas
}

\begin{abstract}
An advantage of first mention-that is, faster access to participants mentioned first in a sentencehas previously been demonstrated only in English. We report three experiments demonstrating that the advantage of first mention occurs also in Spanish sentences, regardless of whether the firstmentioned participants are syntactic subjects, and regardless, too, of whether they are proper names or inanimate objects. Because greater word-order flexibility is allowed in Spanish than in English (e.g., nonpassive object-verb-subject constructions exist in Spanish), these findings provide additional evidence that the advantage of first mention is a general cognitive phenomenon.
\end{abstract}

Languages vary in how much freedom they allow in word ordering (Payne, 1990, 1993; Tomlin, 1986). Despite this, a user of any language might show preferential treatment toward participants presented first in discourse. One such preference is the advantage of first mention, which occurs in both spoken and written language (Gernsbacher \& Hargreaves, 1988; Gernsbacher, Hargreaves, \& Beeman, 1989; Von Eckardt \& Potter, 1985). After comprehending a sentence involving two participants, readers and listeners can more easily access from their mental representation the participant who was mentioned first in the sentence than they can access the participant who was mentioned second. For example, subjects verify that the name "Tina" occurred in Sentence 1 (below) considerably faster than they verify that it occurred in Sentence 2:

Tina beat Lisa in the state tennis match.

Lisa beat Tina in the state tennis match.

This research was supported by Grant $91 / 103$ from the Dirección General de Universidades del Gobierno Autónomo de Canarias and Grant PB93-0562 from the DGICYT, Ministry of Spanish Education (both awarded to MC), and by Grants R01 NS 29926 and K04 NS 01376 from the National Institutes of Health and Grant DASW0194-K-004 from the Army Research Institute (all awarded to MAG). It was presented in September 1992 at the annual meeting of European Society for Cognitive Psychology in Paris, and in November 1992 at the annual meeting of the Psychonomic Society in St. Louis. We are grateful to James Neely, Brian MacWhinney, and Annette de Groot for helpful comments on the manuscript. Requests for reprints should be sent to M. Carreiras, Departamento de Psicología Cognitiva, Universidad de La Laguna, 38200, Tenerife, Spain (e-mail: micarreiras@ull.es) or M. A. Gernsbacher, 1202 W. Johnson Street, University of Wisconsin, Madison, WI 53706-1611 (e-mail: magernsb@facstaff.wisc.edu).
One explanation of this advantage derives from the linguistic structure of English. First-mentioned participants might be more accessible in English sentences because in English declarative sentences, first-mentioned entities virtually always have the syntactic relation known as "subject," and they also typically fill the semantic role known as "agent." However, Gernsbacher and Hargreaves (1988) demonstrated that the advantage of first mention in English does not depend on semantic agency or syntactic subjecthood.

In Gernsbacher and Hargreaves's (1988) study, subjects read sentences similar to the two examples above. Each sentence appeared one word at a time in the center of a computer screen. After the last word of each sentence disappeared, a test name appeared, and the subjects verified whether that name had occurred in the sentence they had just finished reading. In one experiment, Gernsbacher and Hargreaves demonstrated that the advantage of first mention in English does not depend on first-mentioned participants being semantic agents. The test name "Tina" was verified just as rapidly after subjects read Sentence 3 (below), in which Tina is the semantic agent, as they did after they read Sentence 4, in which Tina is the semantic patient:

Tina beat Lisa in the state tennis match.

Tina was beaten by Lisa in the state tennis match.

However, "Tina" was verified less rapidly in Sentences 5 and 6, in which Tina is the second-mentioned participant, than it was in Sentences 3 and 4.

Lisa beat Tina in the state tennis match.

Lisa was beaten by Tina in the state tennis match. 
In other experiments, Gernsbacher and Hargreaves (1988) demonstrated that the advantage of first mention was not attenuated even when the two participants shared subjecthood. For example, "Tina" was still more accessible in Sentence 7 than it was in Sentence 8, even though the two participants, Tina and Lisa, shared syntactic subjecthood in both sentences:

Tina and Lisa argued during the meeting.

Lisa and Tina argued during the meeting.

Gernsbacher and Hargreaves also found that the advantage of first mention was not attenuated even when the first-mentioned participants were not the syntactic subjects of their sentences. For example, the test name "Tina" was verified just as rapidly in Sentence 9 as it was in Sentence 10:

Because of Tina, Lisa was evicted from the apartment.

Tina was evicted from the apartment because of Lisa.

Gernsbacher and Hargreaves (1988; Gernsbacher et al., 1989 ) concluded that the advantage of first mention arises from general cognitive processes and not from language-specific factors (at least, not from those factors that their experiments investigated). However, the advantage of first mention might be unique to speakers of English because English speakers rely on word-order information for sentence interpretation more than do speakers of some other languages (Bates \& MacWhinney, 1987). Therefore, even though English experiments can manipulate semantic agency or syntactic subjecthood to assess the independent contribution of order of mention, English speakers might demonstrate the advantage of first mention because word order is a more important cue in English than it is in other languages (Bates \& MacWhinney, 1987, 1989). As Bates and MacWhinney (1989) observed, "English is the only truly exotic language - the only language we have studied to date in which word order is the most important determiner of sentence meaning across all tested morphological and semantic/pragmatic conditions"' (p. 47). In order to argue that the advantage of first mention is a general, cognitive phenomenon, it is essential to provide supporting evidence from languages with more flexible word order. Gathering such evidence was one goal of the present study.

\section{ENGLISH VERSUS SPANISH WORD ORDER}

Languages differ concerning the presence or absence of linguistic cues, such as word-order constraints or case markings, to indicate who did what to whom. How much importance one places on various linguistic cues is a function of the relative informational value that those cues provide (Bates \& MacWhinney, 1987, 1989). For instance, the same word order, subject-verb-object (SVO), is overwhelmingly used in English; thus, word order is a highly valid cue to sentence interpretation in English. In contrast, word order can be broadly varied for pragmatic purposes in Italian (Bates et al., 1984; Bates, MacWhinney, \& Smith, 1983) and in Spanish (Contreras, 1976; Kail, 1989). In our experiments, we took advantage of the relatively freer word order allowed in Spanish.

Although linguistic typologies classify Spanish as a canonical SVO language, Spanish allows a considerable range of orders, depending on various contextual or pragmatic constraints. For example, the information expressed in the Spanish SVO Sentence 11 can also be grammatically expressed in the Spanish OVS Sentence 12 and in the Spanish VSO Sentence 13:

Juan comió el pescado. (SVO)
John [subject/agent] ate the fish [object/patient].
El pescado lo comió Juan. (OVS)
The fish [object/patient] ate John [subject/agent].
Comió Juan el pescado. (VSO)
Ate John [subject/agent] the fish [object/patient].

Speakers can choose among Sentences 11, 12, and 13, depending on their communicative and pragmatic goals. Perhaps this is why Spanish adult subjects do not rely as heavily on word order to interpret sentences as English adult subjects (Kail, 1989). Thus, Spanish seems an appropriate language to contrast with English.

\section{EXPERIMENT 1}

Our first experiment was designed to replicate in Spanish an experiment conducted by Gernsbacher and Hargreaves (1988), in which both participants shared subjecthood-as in Sentence 14, below:

María y Adela fueron al restaurante.

This type of sentence is a comitative, similar to the English comitatives of Gernsbacher and Hargreaves (1988, Experiment 5). In this type of sentence, both participants are syntactic subjects and both are semantic agents (i.e., both participants act, but not reciprocally). Just as English joins the two elements with the conjunction "and," giving each element equal status, so Spanish joins the two elements with the conjunction "y," also giving each element equal status. Thus, any advantage for the first-mentioned participant will be attributable to order of mention independently of the linguistic constructs of syntactic subjecthood and semantic agency.

\section{Method}

Subjects. The subjects were 50 native Spanish-speaking undergraduates from the University of La Laguna.

Materials. We constructed 32 sentences in which the two participants were agents, sharing subjecthood, and in which the verbs described actions that the two participants engaged in mutually. We assigned two common Spanish first names to each sentence, matching for gender, perceived familiarity, and length (in number of characters). Across all experimental sentences, half the names were female and half were male. Within each sentence, however, the two names were of 
the same gender. One name from each pair was randomly selected as the test name. We then created two versions of each experimental sentence, as illustrated in Table 1 . In one version, the tested name occurred as the name of the first-mentioned participant; in the other version, the tested name occurred as the name of the second-mentioned participant. Thirty-two filler sentences were constructed with test names that had not occurred in those sentences. These sentences resembled the experimental sentences in syntactic form. Two material sets were formed by randomly assigning one of the two versions of each sentence to each material set. Twenty-five subjects were randomly assigned to each material set, so that each subject was exposed to both experimental conditions but to only one version of a sentence.

To ensure adequate comprehension and to encourage the subjects to attend to all aspects of the sentences (not just the names), each experimental sentence was followed by a two-alternative wh... question. About two thirds of the questions were about the locative setting or the action performed in the sentence (for example, "¿A dónde fue Diana?" ["Where did Diane go?"]). The remainder of the questions asked about the identity of the participants (for example, "¿Con quién fue Diana al restaurante?" ["Who went with Diane to the restaurant?"]).

Procedure. Each trial began with a warning signal, which consisted of a plus sign that appeared for $750 \mathrm{msec}$ in the center of the screen. After it disappeared, each word of the sentence appeared (also in the center of the screen). The display time for each word was a function of its number of characters ( $16.667 \mathrm{msec}$ per character) plus a constant $(300 \mathrm{msec})$. The interval between words in the sentences and between the last word in each sentence and its test name was $150 \mathrm{msec}$. The test names appeared in capital letters at the top of the screen and remained on the screen until the subjects responded or $3 \mathrm{sec}$ had elapsed. The subjects responded by pressing one of two response keys, one labeled yes and the other no.

For each experimental sentence, $250 \mathrm{msec}$ after the offset of the test name, the word pregunta (question) appeared toward the bottom of the screen, warning the subjects of an upcoming comprehension question. This warning signal remained on the screen for $750 \mathrm{msec}$, after which the comprehension question appeared, together with two answer choices below it. One answer choice was positioned toward the left side of the screen and the other was toward the right side. The subjects pressed the response key furthest to the left to select the answer on the left, and the response key furthest to the right to select the answer on the right. The correct answer choices appeared equally often on each side of the screen. The questions and answer choices remained on the screen until either the subjects responded or $10 \mathrm{sec}$ had elapsed. After they had responded, the subjects were given feedback about their accuracy.

Four subjects were replaced because they failed to meet the criteria of $90 \%$ accuracy at responding to experimental test names (i.e., those requiring a "yes" response), $90 \%$ accuracy at responding to lure test names (i.e., those requiring a "no" response), and $75 \%$ accuracy at answering the two-choice comprehension questions.

\section{Results and Discussion}

The subjects' average reaction times for correct responses are presented in Table 2. Repeated measures analyses of variance (ANOVAs) were conducted separately across subjects and items. These analyses revealed a reliable effect for order of mention, whereby firstmentioned participants were responded to $57 \mathrm{msec}$ faster than were second-mentioned participants $[F 1(1,49)=$ $15.30, M S_{\mathrm{e}}=5043, p<.0005 ; F 2(1,31)=13.08, M S_{\mathrm{e}}=$ $\left.4084, p<.001 ; \min F^{\prime}(1,73)=7.05, p<.01\right]$. These data replicate in Spanish the advantage of first mention previously found in English. Thus, the advantage of first

Table 1

Examples of Sentence Pairs Used in Experiments 1, 2, and 3

\begin{tabular}{|c|c|c|}
\hline \multirow[b]{2}{*}{$\begin{array}{l}\text { Spanish Sentence } \\
\text { (English Translation) }\end{array}$} & \multicolumn{2}{|r|}{ Test Name } \\
\hline & Name & $\begin{array}{l}\text { Syntactic Position/ } \\
\text { Semantic Role }\end{array}$ \\
\hline \multicolumn{3}{|l|}{ Experiment 1} \\
\hline $\begin{array}{l}\text { Maria y Diana fueron al restaurante } \\
\text { Mary and Diane went to the restaurant }\end{array}$ & $\begin{array}{l}\text { Maria } \\
\text { Mary }\end{array}$ & \\
\hline $\begin{array}{l}\text { Diana y Maria fueron al restaurante } \\
\text { Diane and Mary went to the restaurant }\end{array}$ & $\begin{array}{l}\text { Maria } \\
\text { Mary }\end{array}$ & \\
\hline \multicolumn{3}{|l|}{ Experiment 2} \\
\hline $\begin{array}{l}\text { María invitó a Diana a cenar en casa } \\
\text { Mary invited Diane for dinner at home }\end{array}$ & $\begin{array}{l}\text { Maria } \\
\text { Mary }\end{array}$ & Agent/Subject 1 \\
\hline $\begin{array}{l}\text { A Diana la invitó María a cenar en casa } \\
\text { Diane was invited by Mary for dinner at home }\end{array}$ & $\begin{array}{l}\text { María } \\
\text { Mary }\end{array}$ & Agent/Subject 2 \\
\hline $\begin{array}{l}\text { A María la invitó Diana a cenar en casa } \\
\text { Mary was invited by Diane for dinner at home }\end{array}$ & $\begin{array}{l}\text { Maria } \\
\text { Mary }\end{array}$ & Patient/Object 1 \\
\hline $\begin{array}{l}\text { Diana invitó a María a cenar en casa } \\
\text { Diane invited Mary for dinner at home }\end{array}$ & $\begin{array}{l}\text { Maria } \\
\text { Mary }\end{array}$ & Patient/Object 2 \\
\hline \multicolumn{3}{|l|}{ Experiment 3} \\
\hline $\begin{array}{l}\text { Maria y Diana fueron al restaurante } \\
\text { Mary and Diane went to the restaurant }\end{array}$ & $\begin{array}{l}\text { María } \\
\text { Mary }\end{array}$ & \\
\hline $\begin{array}{l}\text { Diana y Maria fueron al restaurante } \\
\text { Diane and Mary went to the restaurant }\end{array}$ & $\begin{array}{l}\text { María } \\
\text { Mary }\end{array}$ & \\
\hline $\begin{array}{l}\text { La leche y la fruta son alimentos básicos } \\
\text { Milk and fruit are basic food }\end{array}$ & $\begin{array}{l}\text { leche } \\
\text { milk }\end{array}$ & \\
\hline $\begin{array}{l}\text { La fruta y la leche son alimentos básicos } \\
\text { Fruit and milk are basic food }\end{array}$ & $\begin{array}{l}\text { leche } \\
\text { milk }\end{array}$ & \\
\hline
\end{tabular}

*Because of translation constraints, these two sentences that are in the passive voice in English are not passive in Spanish. The passive voice in Spanish would be: "Diana/(María) fue invitada por María/(Diana) a cenar en casa." 
Table 2

Subjects' Average Correct Response Times (RT; in Milliseconds) and Advantage of First Mention (AFM) in Experiments 1, 2, and 3

\begin{tabular}{lccc}
\hline & $\begin{array}{c}\text { RT First- } \\
\text { Mentioned }\end{array}$ & $\begin{array}{c}\text { RT Second- } \\
\text { Mentioned }\end{array}$ & AFM \\
\hline & Experiment 1 & & \\
& 1,102 & 1,159 & -57 \\
Agent/subject & Experiment 2 & & \\
Patient/object & 837 & 883 & -46 \\
& 857 & 891 & -34 \\
Proper names & Experiment 3 & & \\
Object names & 946 & 1,009 & -63 \\
\hline
\end{tabular}

mention is not unique to English, a language in which word order is perhaps the most important cue for sentence interpretation (Bates \& MacWhinney, 1989).

\section{EXPERIMENT 2}

Bates and MacWhinney (1987) and Tomlin (1986) agree that in English, word order is the most reliable cue for identifying the syntactic subject and object because that language has a relatively fixed word order and virtually no case marking, and it is only marginally verbinflectional. In contrast, it is possible in Spanish to deviate from the basic order because other morphosyntactic variables cue the change. For example, the Spanish preposition "a" marks an animate direct object; because the direct object is cued by the preposition "a," the direct object can either follow the syntactic subject, as in Sentence 15, or precede it, as in Sentence 16:

María le pegó a Diana.

Mary [subject/agent] [her] hit at Diane [object/patient].

A Diana le pegó María. At Diane [object/patient] [her] hit Mary [subject/agent].

The grammatical relationship between the elements in these two sentences is identical; in both sentences, María is the syntactic subject/semantic agent and Diana is the syntactic object/semantic patient. Thus, the two sentences are grammatically equivalent, although they serve different discourse pragmatic functions (i.e., in order to emphasize that Diane is the focus of the action, the speaker/writer would produce Sentence 16).

In our second experiment, we took advantage of this special fronting strategy allowed in Spanish, which places the direct object/semantic patient in the first position of a sentence. Although English also allows fronting of the semantic patient in passive voice constructions (e.g., "Diane was hit by Mary"), in an English passive sentence, the first-mentioned participant (in this case, Diane) is still the syntactic subject of the sentence. Thus, even in English passive sentences, order of mention is still confounded with syntactic subjecthood (Gernsbacher \& Hargreaves, 1988). Left-dislocated constructions in English allow first-mentioned participants that are neither subjects nor agents (e.g., "Diane, Mary hit"), but these constructions are atypical. Thus, in Spanish, we can isolate the advantage of first mention from both the advantage of syntactic subjecthood and the advantage of semantic agency.

\section{Method}

Subjects. The subjects were 72 native Spanish-speaking undergraduates from the University of La Laguna. Six subjects were replaced because they failed to meet the criteria described in Experiment 1 .

Materials. We constructed 48 sentence sets; examples appear in Table 1. There were four versions of each experimental sentence. In two of the four versions, the test names were the semantic agents/syntactic subjects of their sentences, and they were either the first- or second-mentioned participants (i.e., the two versions of the sentences designated as Agent/Subject 1 and Agent/Subject 2, respectively, in Table 1). In two other versions, the test names were the semantic patients/syntactic objects of their sentences, and they were either the first- or second-mentioned participants (i.e., the two versions designated as Patient/Object 1 and Patient/Object 2, respectively, in Table 1). Four material sets were formed, so that an equal number of sentences from each experimental condition occurred in each material set. Eighteen subjects were randomly assigned to each material set, so that each subject was exposed to only one version of each experimental sentence.

Procedure. The procedure was the same as in Experiment 1.

\section{Results and Discussion}

The subjects' average reaction times for correct responses are presented in Table 2. A 2 (order of mention: first or second) $\times 2$ (syntactic position/semantic role: subject-agent or object-patient) repeated measures ANOVA revealed a main effect of order of mention $\left[F 1(1,71)=32.21, M S_{\mathrm{e}}=3,239, p<.0001 ; F 2(1,47)=\right.$ $23.26, M S_{\mathrm{e}}=3,295, p<.0001 ; \min F^{\prime}(1,104)=13.51$, $p<.01]$. First-mentioned participants were responded to $40 \mathrm{msec}$ faster than were second-mentioned participants. The main effect of syntactic position/semantic role was reliable in the analysis by subjects, but not in the analysis by items $\left[F 1(1,71)=4.83, M S_{\mathrm{e}}=3,773\right.$, $p<.05 ; F 2(1,47)=1.96, M S_{\mathrm{e}}=4,651, p<1$; $\left.\min F^{\prime}(1,84)=1.39, p<1\right]$. Finally, the interaction between the two variables was not reliable (both $F_{\mathrm{s}}<1$ ). These results suggest that first-mentioned participants acquire a privileged status in comprehenders' mental representations, even when the first-mentioned participants are neither syntactic subjects nor semantic agents.

\section{EXPERIMENT 3}

Our goal in our third experiment was to assess whether the advantage of first mention occurs only with human participants, referred to with proper names. Proper names are often more accessible and available than role names, such as "the waiter" (Sanford, Moar, \& Garrod, 1988). In addition, they are more likely to be 
subjects and agents, to occur at the beginning of their sentences, and to be relied on for the maintenance of referential continuity (Fletcher, 1984; Givón, 1983). Thus, the advantage of first mention might be specific to proper names, regardless of the language.

In Experiment 3, we investigated whether the advantage of first mention also occurs for inanimate objects. Using the same procedure as in Experiment 1, we presented the following type of sentences:

La leche y la fruta son alimentos básicos.

Milk and fruit are basic food.

As in Experiment 1, both the first- and second-mentioned entities (the two inanimate objects) were the syntactic subjects of their sentences, linked by the conjunction "y." Because we also wanted to replicate the results of Experiment 1, we again presented sentences that contained human participants.

\section{Method}

Subjects. The subjects were 62 native Spanish-speaking undergraduates from the University of La Laguna. Seven subjects were replaced because they failed to meet the criteria described in Experiment $\mathrm{I}$.

Materials. The 32 experimental-sentence pairs and the 32 fillers of Experiment 1 were used in this experiment. In addition, we constructed another 32 filler sentences and 32 experimental-sentence pairs in which the names of two inanimate objects shared syntactic subjecthood. Two common Spanish object names, matched for printedword frequency (Julliand \& Chang-Rodriguez, 1964) and character length, were assigned to each sentence pair. One of the object names was randomly selected as the test name for both versions of the sentence. The test name was the first-mentioned object name in one version and the second-mentioned object name in the other version; examples appear in Table 1.

Procedure. The procedure was the same as in Experiment 1.

\section{Results and Discussion}

The subjects' average reaction times for correct responses are presented in Table 2 . Separate analyses were conducted for the proper names and the common object names. The repeated-measures ANOVAs on reaction times for proper names revealed a reliable effect of order of mention, whereby first-mentioned human participants were responded to $63 \mathrm{msec}$ faster than secondmentioned human participants $\left[F 1(1,61)=21.02, M S_{\mathrm{e}}=\right.$ $5,997, p<.0001 ; F 2(1,31)=7.54, M S_{\mathrm{e}}=7,951, p<$ $\left..01 ; \min F^{\prime}(1,54)=5.55, p<.05\right]$. The repeated measures ANOVAs on reaction times for inanimate objects also revealed a reliable effect of order of mention, with first-mentioned inanimate objects being responded to $42 \mathrm{msec}$ faster than second-mentioned inanimate objects $\left[F 1(1,61)=13.71, M S_{\mathrm{e}}=3,985, p<.0005 ; F 2(1,31)=\right.$ $\left.4.76, M S_{\mathrm{e}}=5,862, p<.05 ; \min F^{\prime}(1,53)=3.53, p<.1\right]$. These results suggest that first-mentioned inanimate objects are more accessible than second-mentioned inanimate objects, just as first-mentioned human participants are more accessible than second-mentioned participants. Thus, it is initial constituents - that is, not only human participants, but also inanimate objects - that gain a privileged status in readers' mental representations.

\section{GENERAL DISCUSSION}

The results of all three experiments showed that despite the fact that Spanish speakers place less importance on word order than do English speakers, the same phenomenon exists in Spanish as has been observed with English-namely, that first-mentioned human participants and inanimate objects are more accessible than second-mentioned human participants and inanimate objects. The present cross-linguistic validation allows us to propose that the advantage of first mention is general enough to be attributed to a general cognitive mechanism. According to Gernsbacher (1990), who proposed a structure building framework, "comprehension requires building a mental representation or structure. Building a mental structure requires both laying a foundation and mapping subsequent information onto that foundation. First-mentioned participants are more accessible because they form the foundation of their sentence-level representations, and because it is through them that subsequent information is mapped onto the developing representation" (pp. 24-25).

Other psycholinguists (e.g., MacWhinney, 1987) have also suggested that initial elements play an important pragmatic role, in that they serve as a starting point both for the construction of a speaker's message and for the construction of a listener's representation. Although the order of subject--verb-object predominates over the order object-verb-subject in Spanish, this statistical fact is not to be interpreted mechanically, since the choice of initial element often reflects a communicative strategy on the part of the speaker or writer, who places at the beginning of the sentence the element that he or she thinks is the most interesting. For instance, in Sentence 18, the speaker gives more importance to the time of arriving, whereas in Sentence 19, it is the action that is emphasized, and in Sentence 20, the agent of the action is stressed:
A las siete vendrá Juan.
At seven o'clock will come John.
Vendrá Juan a las siete.
Will come John at seven o'clock.
Juan vendrá a las siete.
John will come at seven o'clock.

Our finding that when they are mentioned first in a sentence, inanimate objects, in addition to proper names, gain a privileged status in comprehenders' mental representations parallels some findings in the spatial-cognition literature. In spatial-cognition tasks, primary nodes (or reference points) anchor information in cognitive maps, and these anchors provide a hierarchical structure for representing and organizing cognitive information about space (Carreiras \& Codina, 1992; McNamara, 1986; Sadalla, Burroughs, \& Staplin, 1980; Stevens \& Coupe, 1978 ). These primary nodes or reference points play an important role in orientation and recall and in the recog- 
nition of other cues. Like these spatial reference points, perhaps, the first elements in sentences, even if they are inanimate objects, act as primary nodes to incorporate subsequent elements into the representation.

Gernsbacher et al. (1989) have suggested that the advantage of first mention is a relatively long-lived characteristic of the mental representation of a sentence. They presented two-clause sentences, such as "Tina gathered the kindling and Lisa set up the tent." While the subjects were still reading the final clause (in the above example, "Lisa set up the tent"), the second-mentioned participant (i.e., Lisa) was most accessible, thereby replicating the well-known clause-recency advantage (Caplan, 1972). However, when testing occurred after the subjects had finished reading the sentences, the advantage of first mention appeared. Moreover, this advantage was not only maintained, it increased at longer intervals (i.e., 1,400 and 2,000 msec after the subjects had finished reading the sentences).

Perhaps the most striking evidence that the advantage of first mention taps readers' mental structure of a sentence was provided by Gernsbacher et al.'s (1989) investigation of two-clause sentences that contained two participants per clause, such as, "Tina and Lisa gathered the kindling, and Mary and Suzy set up the tent." When accessibility of the participants was measured $150 \mathrm{msec}$ after the subjects had read the sentences, two advantages of first mention were observed - one within each clause: "Tina" was more accessible than "Lisa," and "Mary" was more accessible than "Suzy." These data suggest that the verification task, as was employed in the present study, assays readers' mental representation of a sentence, including the clausal structure of the sentence, rather than their ability to provide a simple serial list of the four sentence participants.

Our empirical observations complement the previous observations of the advantage of first mention by demonstrating that the phenomenon is not restricted to the English language. Rather, we conclude that the advantage of first mention is a general cognitive phenomenon.

\section{REFERENCES}

Bates, E., \& MaCWhinney, B. (1987). Competition, variation and language learning. In B. MacWhinney (Ed.), Mechanisms of language acquisition (pp. 157-193). Hillsdale, NJ: Erlbaum.

BATES, E., \& MACWhinNey, B. (1989). Functionalism and the competition model. In B. McWhinney \& E. Bates (Eds.), The crosslinguistic study of sentence processing (pp. 3-73). Cambridge: Cambridge University Press.
Bates, E., MacWhinney, B., Caseli, C., Devescovi, A., Natale, F, \& VENZA, V. (1984). A cross-linguistic study of the development of sentence interpretation strategies. Child Development, 55, 341-354.

Bates, E., MacWhinney, B., \& Smith, S. (1983). Pragmatics and syntax in psycholinguistic research. In S. Felix \& H. Wode (Eds.), Child language at the crossroads (pp. 11-31). Tübingen: Gunter Narr.

CaPLaN, D. (1972). Clause boundaries and recognition latencies for words in sentences. Perception \& Psychophysics, 12, 73-76.

Carreiras, M., \& Codina, B. (1992). Spatial cognition of the blind and sighted: Visual and amodal hypothesis. European Bulletin of Cognitive Psychology, 12, 51-78.

CONTRERAS, H. (1976). A theory of word order with reference to Spanish. Amsterdam: North-Holland.

FLETCHER, C. R. (1984). Markedness and topic continuity in discourse processing. Journal of Verbal Learning \& Verbal Behavior, 20, 564574.

GeRnSBACHER, M. A. (1990). Language comprehension as structure building. Hillsdale, NJ: Erlbaum.

GernsbaCher, M. A., \& HARGREAves, D. (1988). Accessing sentence participants: The advantage of first mention. Journal of Memory \& Language, 27, 699-717.

Gernsbacher, M. A., Hargreaves, D., \& Beeman, M. (1989). Building and accessing clausal representations: The advantage of first mention versus the advantage of clause recency. Journal of Memory \& Language, 28, 735-755.

Givón, T. (Ed.) (1983). Topic continuity in discourse: A quantitative cross-language study. Amsterdam: Benjamins.

Julliand, A., \& Chang-Rodríguez, E. (1964). Frequency dictionary of Spanish words. La Haya: Mouton.

KAIL, M. (1989). Cue validity, cue cost, and processing types in sentence comprehension in French and Spanish. In B. MacWhinney \& E. Bates (Eds.), The crosslinguistic study of sentence processing (pp. 77-117). Cambridge: Cambridge University Press.

MacWhinNey, B. (1987). The competition model. In B. MacWhinney (Ed.), Mechanisms of language acquisition (pp. 249-308). Hillsdale, NJ: Erlbaum.

MCNAMARA, T. P. (1986). Mental representations of spatial relations. Cognitive Psychology, 18, 87-121.

PAYNE, D. L. (1990). The pragmatics of word order: Typological dimensions of verb initial languages. Berlin: Mouton de Gruyter.

PAYNE, D. L. (1993). On the function of word order in Yagua narrative. International Journal of American Linguistics, 59, 1-15.

Sadalla, E. K., Burroughs, W. J., \& STAPlin, L. J. (1980). Reference points in spatial cognition. Journal of Experimental Psychology: Human Learning \& Memory, 6, 516-528.

SANFORD, A. J., MOAR, K., \& GarRoD, S. (1988). Proper names as controllers of discourse focus. Language \& Speech, 31, 43-56.

Stevens, A., \& Coupe, P. (1978). Distortions in judged spatial relations. Cognitive Psychology, 10, 422-437.

TomLIN, R. S. (1986). Basic word order: Functional principals. London: Croom Helm.

Von Eckardt, B., \& PotTer, M. C. (1985). Clauses and semantic representation of words. Memory \& Cognition, 13, 371-376.

(Manuscript received June 10, 1994; revision accepted for publication September 6, 1994.) 